Témoigner Témoigner. Entre histoire et mémoire

Getuigen Revue pluridisciplinaire de la Fondation Auschwitz

$121 \mid 2015$

Violences radicales en scène

\title{
David Foenkinos. Charlotte
}

Paris, Gallimard, 2014

\section{Colette Gutman}

\section{(2) OpenEdition}

Journals

Édition électronique

URL : https://journals.openedition.org/temoigner/3667

DOI : $10.4000 /$ temoigner.3667

ISSN : 2506-6390

Éditeur :

Éditions du Centre d'études et de documentation Mémoire d'Auschwitz, Éditions Kimé

Édition imprimée

Date de publication : 1 octobre 2015

Pagination : 202-203

ISSN : 2031-4183

Référence électronique

Colette Gutman, «David Foenkinos. Charlotte», Témoigner. Entre histoire et mémoire [En ligne], 121 |

2015, mis en ligne le 01 octobre 2016, consulté le 04 février 2022. URL : http://

journals.openedition.org/temoigner/3667; DOI : https://doi.org/10.4000/temoigner.3667

Ce document a été généré automatiquement le 4 février 2022.

Tous droits réservés 


\title{
David Foenkinos. Charlotte
}

\author{
Paris, Gallimard, 2014
}

\section{Colette Gutman}

\section{RÉFÉRENCE}

David Foenkinos. Charlotte. Paris, Gallimard, 2014, 224 p.

1 Ce roman s'inspire de la vie de Charlotte Salomon, peintre allemande assassinée à vingt-six ans, alors qu'elle était enceinte. Il raconte sa brève vie, celle d'une artistepeintre morte en déportation, en laissant derrière elle une œuvre picturale autobiographique d'une extrême modernité. Lorsqu'elle a 8 ans, elle perd sa mère, reste seule avec son père Albert, nommé professeur à l'Université de médecine de Berlin. David Foekinos, comme obsédé par son souvenir, réussit à nous faire connaître celle qui, parmi des millions, a disparu à jamais sans sépulture - mais a cependant réussi à laisser des traces : ses tableaux encore visibles aujourd'hui, au Musée juif d'Amsterdam. Il a retrouvé une photo de classe de Charlotte enfant où « Toutes les jeunes filles fixent l'objectif. Mais les yeux de Charlotte sont tournés dans une autre direction. » Devenue adolescente, elle refuse l'idée de grandir, car rien ne dure et «Il faut vivre à l'abri des déceptions possibles. » David Foekinos rôde autour d'elle, comme si aujourd'hui encore elle était le point fixe de son imaginaire. Sur la route de Charlotte, des hommes, des femmes, ceux et celles qu'elle a connus, sa belle-mère Paula, célèbre et courtisée cantatrice.

2 Charlotte lit beaucoup, avec passion, Goethe, Hesse, Remarque, Nietzsche, Döblin. Elle a peur de l'amour (vivre à l'abri des déceptions), mais elle aime d'un unique amour Alfred, qui va hanter son œuvre, peinte et écrite. Vient le temps de l'affreuse exclusion. Sa vie devient un champ de bataille. Il faut partir. En France. En juin 1940, elle arrive au camp de Gurs, dont elle sera finalement libérée deux mois plus tard, Walter Benjamin se donnera la mort. Elle s'enfuit dans la région de Nice, avec son protecteur, compagnon et bientôt amant, Alexander, sans passion, car elle n'aime qu'un seul homme. Elle a vingt-six ans. Il lui faut du temps pour admettre qu'elle pourrait avoir 
une vie heureuse, ou du moins normale. Elle attend un enfant. Ils se marient. Mais en 1943, les Allemands prennent le contrôle de la zone, avec Aloïs Brunner, le SS peut-être le plus cruel de tous. Il déporte, il déporte. Elle est sans doute dénoncée par quelqu'un du village. Drancy, séparation. Fin de l'histoire. Convoi $n^{\circ} 60$. Après la guerre, revenus de la mort, Albert et Paula envoient à Alfred le catalogue de l'exposition de Charlotte, avec une brochure et une notice biographique. En découvrant les dessins, il se voit représenté partout, et il comprend la place qu'il occupait. Il meurt, en1962, tout habillé sur son lit, avec, dans la poche intérieure près du cœur, la brochure de l'exposition du Musée juif d'Amsterdam - que l'on peut voir aujourd'hui. 